\title{
Hebei Economic Development Countermeasures Study Under the Background of Jingjinji Integration
}

\author{
Chang Xiulian \\ Shijiazhuang Vocational College of Finance, Shijiazhuang City, 050000
}

\begin{abstract}
As a populous province of Hebei, it should enhance its level of development in order to achieve the sound and rapid economic development in the province. But in the actual development, Hebei province did not make full use of the geographic location near the Bohai, Beijing and Tianjin, which leads to large economic differences with Beijing and Tianjin. In recent years, with the regional economic development, Jingjinji integration is becoming a trend, which could better promote the harmonious development of regional economy, and better enhance the quality of the economic development in Beijing and Tianjin. This paper, under the background of Jingjinji integration, finds the problems in the economic development of Hebei province. Then it could make a more scientific development countermeasures, and ultimately achieve rapid economic progress in Hebei Province.
\end{abstract}

Keywords- Jingjinji integration; Regional economy; Hebei Province; Economic development; Countermeasure analysis

\section{INTRODUCTION}

Introduction: Regional economic integration is that neighboring countries, in order to safeguard the common interests and strengthen economic ties and cooperation through covenants and agreements, in the region gradually eliminate trade and non-trade barriers between member states, further coordinate social and economic policies among the member countries, form a cross-border unified economic area. Currently, Jingjinji region has become one of the three major economic growth in China's economic development. Therefore, promoting Jingjinji regional economic integration is particularly important.

\section{The POSITION AND ADVANTAGES OF Hebei PROVINCE IN JINGJINJI INTEGRATION}

\section{A. The position of Hebei Province in Jingjinji integration}

Surrounded by Beijing and Tianjin, Hebei Province is an important hinterland, with an important strategic position in the Beijing-Tianjin Bohai Sea area. In the "Jingjinji Metropolitan Area Regional Planning ", there are eight cities in Hebei were positioned to be heavy chemical industry base in raw materials, modern agricultural base and an important tourism and leisure area, and they also research and development, transformation and processing matching base of the Beijing-Tianjin high-tech industries and advanced manufacturing. May 2010, "Jingjinji Metropolitan Area Regional Planning" has been submitted to the State, indicating that the coordinated development of Jingjinji Zone has become part of national development strategies. Therefore, it is necessary to analyze the development strategy in Hebei,in the background of Jingjinji regional economic integration.

\section{B. The advantages of Hebei Province in Jingjinji integration}

Hebei Province has a unique geographical advantage, because it is the only province that surrounds a special surround of Beijing and Tianjin and also Bohai Bay in the east. Surrounded by two municipalities of Beijing and Tianjin, enclosed with two historic city, on the one hand, Hebei has political, economic and cultural components of the capital city, on the other hand there are the port city of Tianjin resources reserves. There are ups and downs Great Wall, the vast fertile North China Plain, rippling rich Bohai Sea, road and rail network criss-crossing in Hebei, which is not only a transport aircraft through the national channels of Beijing, Tianjin, but it makes Hebei become a broader strategic market for the capital Beijing outward expansion.

Resources advantages. Hebei Province is the only province in coastal plains, lakes, hills, mountains, plateaus, and it has rich marine living resources and marine mineral resources, from north to south, along the Bohai Bay, there is dotted with Shanhaiguan, Qinhuangdao Port, Jingtang Port, Caofeidian Port and Huanghua Port with a total quay (berth) 58. There are huge annual handling capacity, now incorporated into the national development strategies Caofeidian,Ore wharf is a deep-water port in northern China's most privileged address.

Infrastructure advantages. Currently, the infrastructure has made significant progress in Hebei Province, BeijingShijiazhuang Passenger Line, North Water Transfer Project in Hebei section of other key projects got to accelerate, the province built 2,021 km highway, port cargo throughput of 500 million tons, the new installed electricity capacity of 6,000,000 kilowatts. Relocation of Shougang, Caofeidian Port supporting construction and other projects have been completed.

Processing and manufacturing advantages. After decades of reform and opening, Hebei Province industrial structure has formed a complete ranges and some basic industrial system, He becoming an active force in Hebei Province to speed up economic development. 


\section{THE PROBLEMS OF ECONOMIC DEVELOPMENT IN} HEBEI

\section{A. Irrational industrial development}

Because of Jingjinji geographical relations, it results that Hebei's advantage industry did not have a competitive advantage in the economic development. Local resources in
Hebei also continue flowing to Beijing and Tianjin, which caused unreasonable state in Jingjinji industrial development. In the Jingjinji region Hebei Province is the lowest level of economic development. Secondary industry is relatively well-developed, tertiary industry is relatively backward and primary industry is very high, which reflects that in the economic development the process of urbanization lags far behind the process of industrialization. See Table 1:

Table 1 Comparative analysis of three industrial structure

\begin{tabular}{cccccc}
\hline & 2004 & 2005 & 2006 & 2007 & 2008 \\
\hline Beijing & $2.4: 37.6: 60.0$ & $1.4: 29.4: 69.2$ & $1.3: 27.8: 70.9$ & $1.1: 26.8: 72.1$ & $1.1: 25.7: 73.2$ \\
Tianjin, & $3.5: 53.2: 43.3$ & $3: 56: 41$ & $2.7: 57.3: 40$ & $2.1: 57.6: 40.3$ & $1.9: 60.1: 38.0$ \\
Hebei & $15.6: 52.9: 31.5$ & $14.9: 51.8: 33.3$ & $13.8: 52.3: 33.9$ & $13.2: 52.8: 34.0$ & $12.6: 54.2: 33.2$ \\
\hline
\end{tabular}

The proportion of service industry is low. Added value accounted for $31 \%$ of the province's GDP, which is below the national average. Industrial concentration is low, scale is small and scattered is layout.Electronic equipment manufacturing industry accounted for only $0.8 \%$ of industrial added value. In addition, Hebei stimulating effect of consumer demand is relatively weak. The unbalanced natural basic conditions form an unbalanced layout situation.

\section{B. Regional factor's lack of configuration}

Beijing and Tianjin occupy absolute advantage of capital, technology and talent, while Hebei Province has severe shortage of these elements. Development of Beijing and Tianjin is also subject to Hebei's overall containment of "soft and hard environmental constraints", which limited the leapfrog development of Beijing and Tianjin. Hebei's poor economic strength is a major obstacle. As an example of "Yangtze River Delta", in order to achieve the development of their own development strategies Jiangsu, Zhejiang and Shanghai in recent years in the development of all the three parties ultimately come together.This is a worthy lesson to Hebei.

\section{Table 2.Service industry of Hebei and four coastal provinces in GDP}

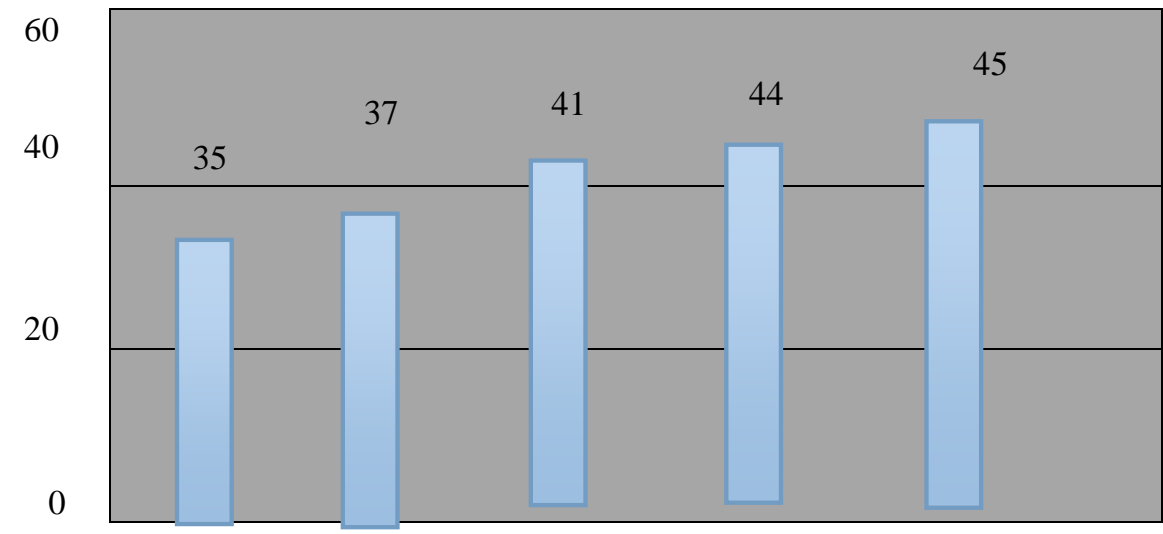

Hebei Shandong Jiangsu Zhejiang Guangdong

\section{Technology and equipment level of enterprise is backward}

Technology and equipment level of enterprise is backward and extensive economic issues highlighted. The technology and equipment which meets international and domestic advanced level are less than $20 \%$, which is lower than the national average of 14 percent. In Hebei Province, the overall scientific and technological innovation capability is not high. Industrial technology innovation capability and capacity for independent innovation is very weak, which did not suited to the needs of regional competition.

\section{Investment structure is not reasonable}

Import and export volume is small, and export way is relatively simple. Proportion of investment in modern 
services is small and the share of state-owned economy is still too large. Hebei province's economic strength and technological strength are very far from Beijing-Tianjin, and basis for cooperation is relatively weak. Meanwhile, Hebei has less effective way to achieve economic integration with Beijing and Tianjin. Hebei should vigorously develop the domestic demand and encourage the development of private enterprises and SMEs. Therefore, to achieve leapfrog development in Hebei Province, we must seize the current favorable opportunity to take the comparative advantages of location and resources, etc.

Table 3.Fixed asset investment of Hebei and four coastal provinces in GDP

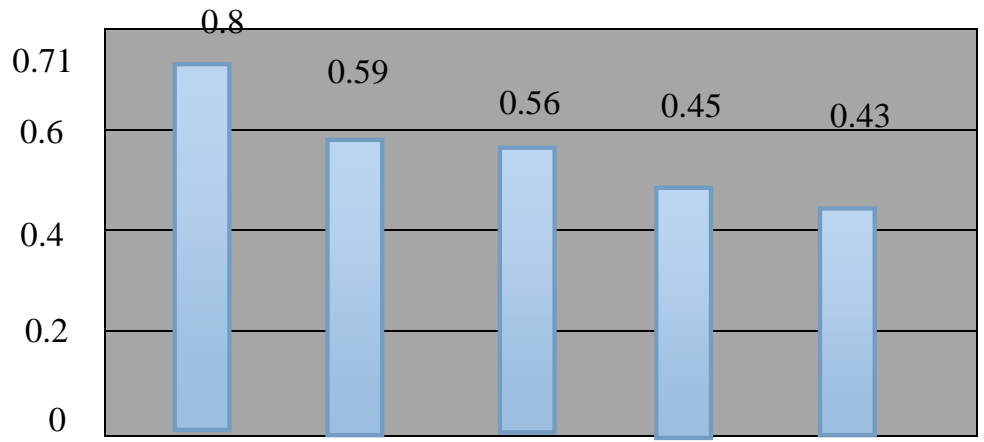

Hebei Shandong Jiangsu Zhejiang Guangdong

\section{HEBEI ECONOMIC DEVELOPMENT COUNTERMEASURES UNDER THE BACKGROUND OF JINGJINJI INTEGRATION}

\section{A. Build service-oriented government, optimize the industrial structure}

Hebei should gradually transform government functions, shifting government from "building type" to the "serviceoriented". Due to historical reasons, the proportion of stateowned economy in Hebei is high. The government has great impact on the economy. However, at present, Hebei already has a good infrastructure and industrial base, so government should decrease the direct intervention in the economy. Hebei should vigorously develop the domestic demand and encourage the development of private enterprises and SMEs. It should seize the opportunities that country is vigorously developing strategic emerging industries to guide the development of new industries around. Encourage production and research cooperation and improve economic efficiency is the key issue in Hebei. Although the economies scale of Hebei are in the forefront of the country, there is still a large lack of economic efficiency and structure. So Hebei needs achieving efficiency and improving the structure. Only in this way can they increase income, improve the level of urbanization, form a virtuous circle, and achieve organic growth. Government should further improve and maintain good business environment, promote industrial structure optimization, improve incomes and living standards.

\section{B. Improve the government's planning and guidance, promote balanced regional development}

Take full advantage of features of different regions to develop regional overall development plan. Take full advantages of the three major ports of Qinhuangdao,
Caofeidian, Huanghua and vigorously develop the port economy and commodity trade.Promote agglomeration of related industries and factories. Seize the opportunities that country is vigorously developing strategic emerging industries to guide the development of new industries around. Encourage production and research cooperation and improve economic efficiency is the key issue in Hebei. Vigorously develop modern agriculture and strategic emerging industries, to promote the rapid development of underdeveloped areas.

\section{The introduction of high-tech and the development of tertiary industry}

In terms of high-tech industries and high-tech personnel training, undoubtedly Beijing and Tianjin were far ahead of Hebei Province, but there is a vast land in Hebei, where they can build industrial park. Hebei Province should strengthen the introduction of talent, and inhibit brain drain. Promote scientific and technological progress in many aspects, while improving technology park construction. Hebei should vigorously develop the domestic demand and encourage the development of private enterprises and SMEs. For the services sector, Hebei should focus on developing their own advantage industry in province which matches services, or it could take Hebei Province's own use of natural and human resources to create unique tourism and leisure industry.

\section{Enhance the open level, guide the development of industrial agglomeration}

Hebei should improve the openness, by the force of developed countries, and developed regions of the country to promote local economic development. With the increased cost elements and government policies'changing, a large number of companies began to shift to inland and northern provinces. Hebei should vigorously develop the domestic 
demand and encourage the development of private enterprises and SMEs. Hebei should seize this opportunity to upgrade the industry level, and promote the development of private economy. Optimize the business environment and strive to form 10 key parks that the output value is more than 100 million. Try efforts to build Qinhuangdao Development Zone, Langfang Development Zone, Baoding Development Zone, Shijiazhuang Hi-tech Zone, Dan Economic Development Zone, Tangshan City, EMU, Yanjiao Development Zone, Baoding Great Wall industrial zone, Dingzhou Tanghe circular economy industrial park, west of Qian'an industrial Zone, Laoting New Harbor industrial zone and other high-tech parks.

\section{SUMMARY}

In summary, under the concept of "Jingjinji integration" strategy development, Hebei Province should clear positioning of of their services for Beijing and Tianjin, and learn to see opportunities. Meanwhile under the backdrop of the regional coordination and common development, it should pay attention to their own development conditions. Select the right economic development strategy for Hebei Province. Strengthen the position of pillar industries, and develope diversified economic situation. Then it could improve the economic strength and people's living standards,and achieve the overall strength of the overall balanced development for Beijing and Tianjin.

\section{REFERENCES}

[1] Liu Bangfan. Hebei coastal areas development and Jingjinji regional economic integration Research Review [A]. Yanshan University School of Law. Learning "the eighteen" spiritual and Hebei coastal areas development forum proceedings [C]. Yanshan University School of Law. 2012.21.

[2] Li Hong. Under the background of Jingjinji integration port Logistics Development Strategy Research [J]. Logistics Technology, 2014, 02;134-136.

[3] Li Man. Development research of Jingjinji regional economic integration [D]. Tianjin University, 2005.

[4] Zhang Xiaomeng. Xingtai City Development Strategies under the background of Jingjinji regional integration [D]. Northeast Normal University, 2009. 